\title{
A Guideline of Using Case Method in Software Engineering Courses
}

\author{
Dzulaiha Aryanee Putri Zainal ${ }^{1}$, Rozilawati Razali ${ }^{1} \&$ Zarina Shukur $^{1}$ \\ ${ }^{1}$ Faculty of Information Science and Technology, Universiti Kebangsaan Malaysia, Bangi, Malaysia \\ Correspondence: Dzulaiha Aryanee Putri Zainal, Research Center for Software Technology and Management, \\ Faculty of Information Science and Technology, UKM, Bangi 43600, Selangor, Malaysia. E-mail: \\ dzulaiha.aryanee@gmail.com
}

Received: July 14, 2014 Accepted: August 19, 2014 Online Published: September 23, 2014

doi:10.5539/ies.v7n10p50 URL: http://dx.doi.org/10.5539/ies.v7n10p50

\begin{abstract}
Software Engineering (SE) education has been reported to fall short in producing high quality software engineers. In seeking alternative solutions, Case Method (CM) is regarded as having potential to solve the issue. CM is a teaching and learning (T\&L) method that has been found to be effective in Social Science education. In principle, instructors should be guided appropriately in order to adopt CM in T\&L. SE education however lacks of such guidelines. This paper addresses this concern by identifying the factors and their corresponding elements and conditions that contribute to the effective use of CM in T\&L SE courses. The factors, elements and conditions were then collated as a framework in the form of a guideline. The factors, elements and conditions were gathered through a series of studies, namely a theoretical study, two surveys and two expert reviews. The theoretical study involved reviewing previous research, while the surveys were performed with five groups of students who experienced CM in learning SE courses. The students were from various education and work backgrounds. Two types of survey instruments were employed, which are questionnaire and group interviews. To form the guideline, the gathered data were analysed qualitatively using contents analysis. The guideline was then validated by two experts through expert reviews. There are four main factors that constitute the guideline of using CM in T\&L SE courses: Case, Instructor, Student and Infrastructure. Each factor has its corresponding elements and conditions. The guideline is useful for SE instructors to adopt CM in T\&L SE courses at their institutions.
\end{abstract}

Keywords: case method, empirical study, qualitative, software engineering

\section{Introduction}

Software products have become crucial throughout the nation's everyday life. The growth in the use of software products has indirectly demanded reliable, efficient and knowledgeable software engineers. This requires the education system to produce better trained software engineers. In order to fulfil this expectation, the education system is continuously researching for the best technique to teach future software engineers. One method that is evidently effective in Social Science education is Case Method (CM). The method is now gradually being applied in Software Engineering (SE) education. In fact, recent studies indicate that the method is as equally successful in SE domain (Garg \& Varma, 2007; Jianmin \& Jian, 2010).

To ensure a successful CM implementation in teaching and learning (T\&L) SE courses, instructors should follow a certain guideline. The guideline should contain factors and elements that are necessary in a CM T\&L environment. At present, there is a lack of such guidelines in SE education. Formulating a practical guideline requires not only a theoretical investigation but also a series of empirical work that gather evidence from users and experts. The main objective of this paper is to propose a guideline of adopting CM in T\&L SE courses. The guideline was derived from a series of work including a theoretical study, two surveys and expert reviews.

This paper is organised as follows. Section 2 presents the background of CM, SE and the use of CM in SE education. Section 3 elucidates the methodology used in the study, namely the theoretical study, surveys and expert reviews. Section 4 describes the findings of the work by presenting the guideline with its descriptions whereas Section 5 explains briefly some of the validity threats. Finally, Section 6 concludes the paper with a summary that outlines the main findings and future work.

\section{Background}

This section contains the background information about CM, SE and the related work on using CM in SE education. 


\subsection{Case Method}

CM is a T\&L method in delivering a subject. It uses real scenarios in the form of a case study (Dooley \& Skinner, 1977). CM is able to relate knowledge and actions (Volpe, 2002). It was firstly introduced at Harvard Law and Business School almost a hundred years ago. In view of the fact that it was found effective as a T\&L tool, it was then applied in other education areas such as medical (Herreid, 2005), management, nursing, computer science, information systems and telecommunications (Golich, Boyer, Franko, \& Lamy, 2001).

Case study can be used either in research or education (Strach \& Everett, 2008). In the context of CM, the case study is referred to as a case. A case is a narrative about how something exists in the context of the world at a certain stated time. The plot in a case is based on experiences by a real individual who faces a dilemma or an uncertain situation (CAPAM, 2010). That individual is called the protagonist. In a CM T\&L environment, students have the opportunity to experience the dilemma faced by the protagonist and ultimately make decisions or perform actions in solving the problem at hand (Leenders, Erskine, \& Mauffette-Leenders, 2007). Apart from the case itself, another vital element of CM is the discussion. CM works best in group settings where students can share and learn from each other.

\subsection{Software Engineering Education}

$\mathrm{SE}$ is an engineering discipline that involves theories, methods and tools in the development and maintenance of a software system (Sommerville, 2010). It concerns the aspects of producing a reliable, efficient and usable system. SE also involves project management, change management and people management in dealing with challenges in software development and maintenance processes (Shackelford et al., 2005).

Most systems are critical in nature which can cause major impacts if they fail. Thus, such systems must be developed by skilled and knowledgeable workforce (Shackelford et al., 2005) who are called software engineers. Software engineers are the individuals who are responsible of developing software from the beginning phase until its deployment. They have to analyse problems as well as applying their knowledge and skills in proposing creative solutions. Software engineers normally work in groups, which require them to obtain good communication and high interpersonal skills. During their career, there would be times that they need to attain new knowledge. Hence, they should have self-learning capabilities (Garg \& Varma, 2007; Jianmin \& Jian, 2010). Software engineers also often face dilemma in making decisions. They should be well trained in making decisions and selecting the best solutions or technology for the problem at hand. SE education therefore has to emphasise the core principles of software development, maintenance and management in a practical manner (Joint Task Force on Computing Curricula, 2004).

The current T\&L methods in SE education are reported as less competent in producing high valued software engineers (Garg \& Varma, 2007; Varma \& Garg, 2005). Due to massive knowledge and skills contained in SE domain, the subject becomes too theoretical and lacks practical elements. The present T\&L methods are based on physical classes that use whiteboard and projectors. Students attend classes, listen to lectures, memorise and regurgitate their knowledge in written examinations. They become passive listeners and their thinking capabilities are limited (Jia, 2010). Learning gradually becomes a one way process whereby students are not engaged actively in exploring knowledge. According to cognitive psychologists and learning scientists, this type of learning method is ineffective (Garg \& Varma, 2007). In essence, SE students should learn how to apply fundamental knowledge in solving and making decisions for real problems (Joint Task Force on Computing Curricula, 2004). They therefore must have a close experience with SE profession through practical experiences (Hilburn, Towhidnejad, Nangia, \& Li, 2006).

\subsection{Case Method in Software Engineering Education}

A number of studies have attempted to improve the education systems for computing courses in industries or at the universities (Fuller, Croll, \& Limei, 2002; Hilburn, et al., 2006; Jia, 2010; Lin, 2010). One of the methods is by using a pedagogical approach called CM (Dooley \& Skinner, 1977). T\&L via CM is considered to be more meaningful as it combines theory and practical elements. The method also fosters student centred learning whereby students are involved actively in the learning process. It also develops students' skills in decision making, problem solving, critical thinking, analytical thinking, group work and various interpersonal skills. CM has been effective in some areas of education such as law, medical sciences and management (Garg, Varma, Giridhar, \& Mishra, 2006). However, its use in applied science education such as SE is still limited (Hilburn et al., 2006).

Previous studies on CM in SE were either about case development (Hilburn \& Towhidnejad, 2007; Razali, Zainal, \& Chitsaz, 2012) or case usage in T\&L SE (Garg \& Varma, 2007, 2009; Varma \& Garg, 2005). For the 
latter, there is no one specific approach of using CM in SE. However, most researchers agreed on the following procedure. Each step varies in how it is being conducted:

a) Students are given a case.

b) Students understand and analyse the cases individually.

c) Students will then discuss in small groups and in the classroom.

d) The instructor will guide the students throughout steps a) to c).

e) Students write reports.

The implementation of CM can be combined with tutorials and conventional classes (Lin, 2010). Most cases are given to students in the form of printed text. Other forms of cases include video simulation (Lin, 2010; Yu, 2010), digital format (Smith, Vega, \& McCrickard, 2008), multimedia (Carroll \& Rosson, 2006; Taran, Miller, Seela, \& Shojaeddini, 2009) or web-based (Taran et al., 2009). Cases can also contain images, audio and video to engage students (Taran et al., 2009). Past studies have shown that the case used in CM should have certain criteria in order for it to be useful. Cases should contain realism which means it is based on real events, experiences and scenarios. Real scenario in a case makes students engaged in solving the case (Hilburn \& Towhidnejad, 2007). Cases should contain local elements, appealing to students, timely, adhere to curriculum contents, format and course objectives. It should also contain basic concepts and principles, developed specifically for a group of students (Bolinger, 2011) as well as it should be complete (Hilburn \& Towhidnejad, 2007). Cases should be relevant to current issues (Bolinger, 2011; Bolinger, Yackovich, Ramnath, Ramanathan, \& Soundarajan, 2010) and contains familiar characters (Bolinger, 2011). Several studies have found that cases in modular forms or short stories are suitable for introductory courses (Bolinger, 2011; Carroll \& Rosson, 2006). To assist the students, cases can be accompanied by a series of related questions as guidance for them in analysing the cases. Open questions however are not suitable for students who are new to CM (Burge \& Troy, 2006; Wang \& Yang, 2010). In addition, students can be given supporting documents such as project artefacts (Carroll \& Rosson, 2006; Hilburn \& Towhidnejad, 2007; Hilburn et al., 2006) as well as additional reading suggestions (Tan \& Teo, 2009). Cases should also synchronise with other T\&L materials such as course notes (Burge \& Troy, 2006). A course can cover one case for each major topic, thus a few cases ends up covering multiple topics. It is quite infeasible to cover the entire syllabus by using a single case (Garg \& Varma, 2007).

The point of time to introduce cases to students also plays an important role. Most studies stated that the cases should be given to students before the discussion sessions so that they have ample preparation time (Burge \& Troy, 2006; Garg \& Varma, 2007; Jianmin \& Jian, 2010). There are studies which suggested that the case should be given in the early semester with the purpose of familiarising it to the students (Lin, 2010). Cases should also be small but adequate enough (Garg \& Varma, 2009). Otherwise, students will take a long time to read and understand the contents. Students ought to have some background knowledge of the subject (Konsky, Ivins, \& Gribble, 2007; Ramnath \& Dathan, 2008; Tan \& Teo, 2009) to help them learn through cases. Having background experience in software development is also an advantage (Garg et al., 2006).

In CM, students should be responsible for their learning. After being given the case, students read and find useful information when analysing the case (Jianmin \& Jian, 2010). Students should pay attention and identify the protagonist who is facing the problems in the case. They should try to experience the problems that the protagonist is facing (Garg \& Varma, 2007) and later, formulate some solutions to the problems. The students should form a group of not more than five people and appoint a leader. In that small group, students discuss, exchange views, ideas and analyse each solution before coming to a final conclusion. These processes take place within a week before the discussion session. If the class size is too large, only a few groups are selected at random to present in class. This implicitly indicates that in order for the whole group to have a chance to present, the class size should be kept small (Garg et al., 2006). After the presentation, the whole class should engage actively (Rongchun \& Lixin, 2008) in the discussion by contributing views and ideas. Each contribution is rewarded by the instructor. To allow this, it is recommended that students wear nametags in order for them to be easily recognised and remembered (Golich et al., 2001). At the end, each student has to write a report based on their individual solutions together with the discussed solutions.

The efficacy of $\mathrm{CM}$ is also influenced by the instructors. Case instructors should understand the underlying concepts of CM, the case itself and the course contents very well. They must analyse the main topics, hidden theories and principles before using CM in the classroom (Rongchun \& Lixin, 2008). The instructors' main task is to deliver the case to students (Wang \& Yang, 2010) by explaining the case storyline and guiding them on how to analyse it. They act as facilitators that ensure lively discussions and avoid any deviation from the original 
topic. They should encourage students to be involved in the discussions. Instructors should ask exploratory and relational questions that reason out solutions. They are prohibited to give out ideal answers to the case problems (Garg \& Varma, 2007) and must be fair (Garg et al., 2006) in the assessments. The instructors should interact with the students and have a close teacher-student relationship that keeps students engaged in the discussions. At the end, the instructors should summarise and conclude the discussions based on the students' responses. It would be an added advantage to the discussions if the instructors possess several years of work experience in industry (Hilburn \& Towhidnejad, 2007). As guidance to the instructors, teaching cases are usually equipped with teaching notes that contains the main and supplementary resources to help instructors deliver and conduct CM (Razali, Zainal, \& Chitsaz, 2012).

The theoretical analysis above indicates that there are a number of elements and conditions that contribute to the efficacy of CM in T\&L SE courses in general. The elements can be classified into four main factors, namely Case, Instructor, Student and Environment. Figure 1 illustrates the factors and elements found from previous studies.

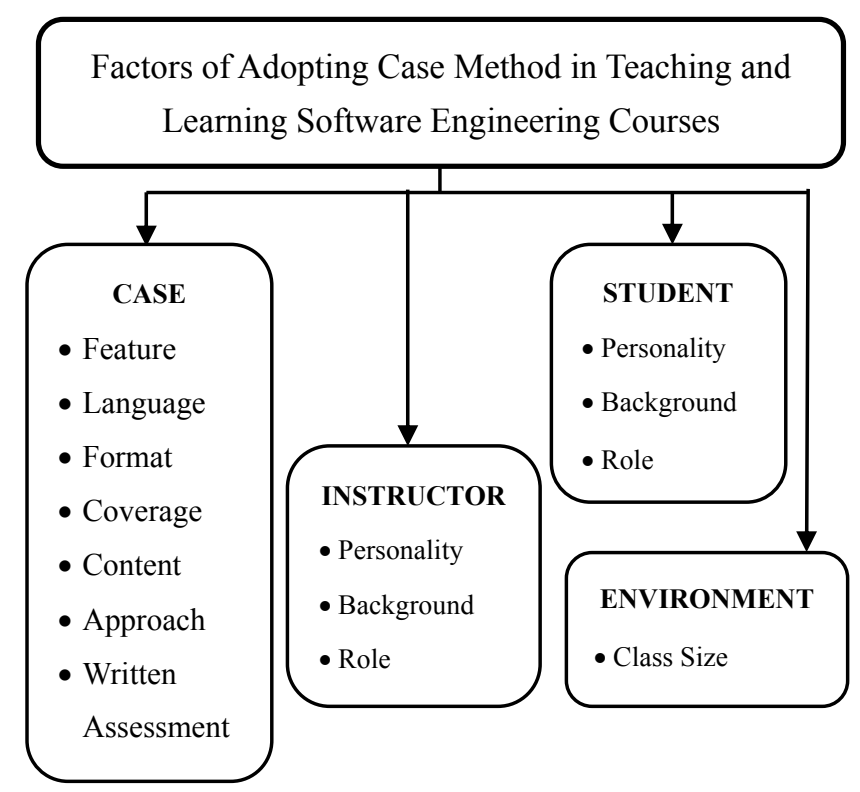

Figure 1. Conceptual model

\section{Method}

The main objective of the study was to propose a guideline on how to use CM in T\&L SE. The guideline is expected to be a reference to SE instructors when they use CM in delivering SE courses. The study therefore aimed to answer the following research questions:

- What are the necessary elements for adopting CM as a $T \& L$ tool for $S E$ courses?

- How can the elements be categorised into a set of contributing factors and form a guideline of adopting CM in T\&L SE courses?

The study involved four phases, namely a theoretical study, a series of surveys (Survey 1 and 2) and expert reviews, as depicted in Figure 2. The following paragraphs explain the activities in each phase. 


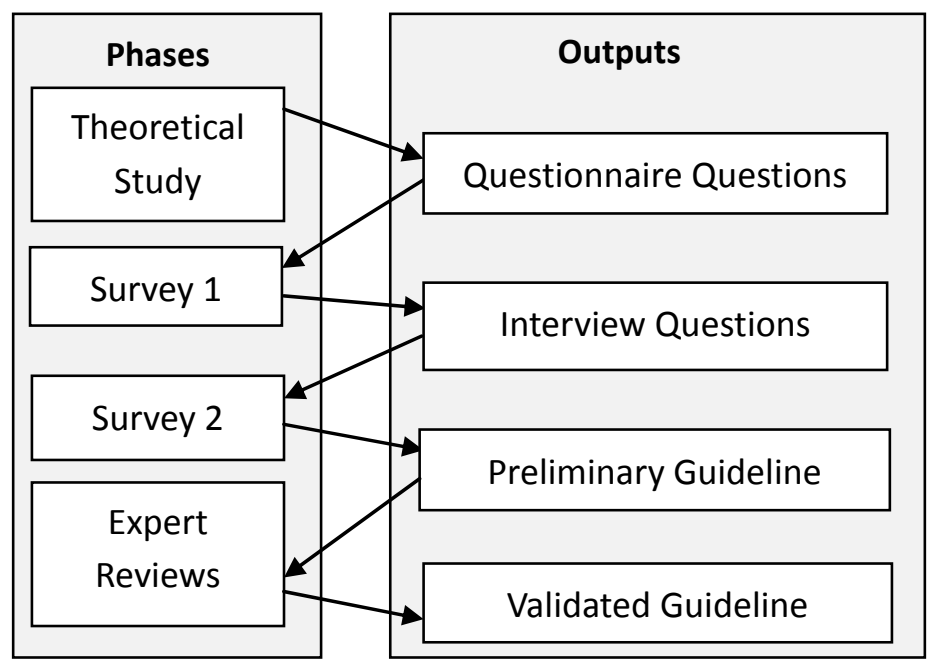

Figure 2. Research phases

\subsection{Theoretical Study}

A theoretical study was executed to gather the elements that are involved in CM T\&L environment for SE education. The first step was to investigate how SE instructors currently use cases in T\&L SE courses. A research question for the theoretical study was derived in order to guide the searching, which is "What are the studies concerning case method in SE education?" The research question was a starting point in determining the search strings to collect articles from various databases. The search strings used were ("case method" OR "case teaching" OR "teaching case" OR "case study") AND ("education" OR "teaching" OR "learning") AND ("software engineering" OR "SE"). The locations of search were in the following databases: IEEE Explore, ACM Digital Library, Science Direct, Scopus, Springer Link, Google Scholar and ISI Web of Science Proceedings. The study used the following inclusion and exclusion criteria throughout the search process:

- $\quad$ The inclusion criteria were:

a) Only articles in journals and proceedings.

b) Articles about using cases in teaching and learning.

c) Articles written between 1st January 2006 and 31st December 2011.

- $\quad$ The exclusion criteria were:

a) Title and abstract of articles that obviously do not meet the main research question.

b) Articles about studies that were executed outside of higher education institutions.

c) Duplicated articles.

d) Articles written in languages other than Bahasa Malaysia (Note 1) and English.

e) Articles concerning case study used in research (unless it is a case study on CM).

f) Articles without the full text.

By using the search strings stated earlier, 394 articles were found. Six duplicated articles were excluded and left with 388 articles. Through exclusion and inclusion process based on titles and abstracts, 359 articles were excluded resulting in 29 articles. The full contents of these 29 articles were then read whereby 6 more articles were rejected. These remaining 23 articles were then analysed. The theoretical study also includes articles about case method in general. The articles included in the analysis have been discussed in Section 2 above.

The data gathered from the selected articles were analysed by using contents analysis (Krippendorff, 2013). The analysis started with a theory as guidance for initial codes. The theory used in the study was "Learning using cases requires students and instructors to be in a predetermined learning environment." Later, the data in the text were categorised as manifest and latent contents. The former is the specific, clear, surface contents that are easily categorised whereas the latter refers to the underlying meaning contained in a reference text. In order to identify both contents, deductive and inductive approaches were adopted in the analysis procedure. By applying the deductive approach based on the theory, four main factors were identified: Case, Instructor, Student and 
Environment. They are indeed the manifest content. On the other hand, a statement from (Hilburn \& Towhidnejad, 2007) that states "Real scenario in a case makes students engaged in solving the case" is an example of latent content. The statement was summarised and labelled as "Realism". As realism indicates one requires case feature for $\mathrm{CM}$ to be effective, a conceptualised element called "Feature" under "Case" factor was created. In other words, "Realism" is the characteristic or condition of "Feature" element for "Case" factor. This synthesis process was achieved using inductive approach. The process of coding and abstracting was repeated until the data reached its saturation period. The result of the analysis is the conceptual model, as illustrated in Figure 1. The figure only illustrates the factors and elements. The conditions for each element are discussed in Section 4.

\subsection{Surveys}

This section explains two surveys that were conducted after the theoretical study phase.

\subsubsection{Survey 1}

A survey was conducted by means of an open-ended questionnaire consisting of four questions based on the conceptual model derived from the theoretical study. The objective of the survey was to assess students' acceptance towards CM in T\&L SE in general. By indicating the acceptance levels, the participants were then required to explain the underlying reasons behind such preferences. Through the reasoning, some elements were identified.

The participants were conveniently sampled. They comprised three groups of students that had experienced learning using CM in SE courses in a public university in Malaysia. The students consisted of 10 Executive Masters, 32 Executive Undergraduates and 14 International Undergraduates, which totalled up to be 56 participants altogether. 'Executive' refers to part-time and mature local students whilst 'International' denotes non-Malaysian students. The data from Survey 1 were analysed qualitatively using contents analysis and quantitatively using descriptive statistics.

It was concluded that students accept $\mathrm{CM}$ with certain predefined conditions. They accept $\mathrm{CM}$ due to its characteristics and circumstances during its execution. Among the reasons why students perceive CM as useful are its realness as well as the knowledge and understanding gained during the process. Students accept case discussions as written individual assessments, if the cases are short and simple; involve thinking and less memorisation; and contain sufficient information. Students are willing to participate in discussions, only if instructors assess their commitment and reward them appropriately. In addition, instructors must also provide timely feedback and guide the discussions. The discussions could become more meaningful if students possess some industrial work backgrounds or experience. Finally, the environment should be conducive, that is, fun and relaxing. The detailed information about the survey can be found in (Razali \& Zainal, 2013a).

\subsubsection{Survey 2}

The objective of Survey 2 was to identify the corresponding characteristics or conditions for each identified element that contributes to the efficacy of CM in T\&L SE courses. In addition, it was intended to further refine the acceptance conditions that were found in Survey 1. The data were collected by means of two group interviews with two different sets of students and were analysed qualitatively using contents analysis. The interviews utilised semi-structured and open-ended questions, which were specially designed to investigate the conditions that must be fulfilled for the successful use of CM in T\&L SE courses. The participants consisted of 34 Executive Undergraduates and 30 full-time Undergraduates from the same university as in Survey 1. They were multi-racial locals. 'Multi-racial' stands for the mixed races of Malay, Indian and Chinese whilst 'locals' denotes Malaysians. Both groups of participants had experienced learning and using CM in SE courses. They were different sets of samples, not among the students participated in Survey 1. The time lag between Survey 1 and 2 was about one year. Prior to the interviews, a pilot study was conducted to ensure the validity of the questions. The elaboration about the survey including the rationale behind the 'Multi-racial' criteria can be found in (Razali \& Zainal, 2013b).

\subsection{Expert Reviews}

This section elaborates two expert reviews that were conducted after formulating the preliminary guideline.

\subsubsection{Data Collection}

Based on the findings of the theoretical study, Survey 1 and Survey 2, a preliminary guideline of adopting CM in T\&L SE courses was constructed. The guideline was then presented to two experts denoted as Expert A and Expert B for validation purposes. The session is referred as an expert review. The expert review was necessary to 
ensure the feasibility of the guideline such as the accuracy of the concepts and the suitability of factors, elements and conditions. Expert A was a senior lecturer and Expert B was a mature Master student, both at a public university in Malaysia.

They were selected because they had a significant amount of experience in using CM in T\&L SE courses. Both experts also had more than five years' experience of being software engineers. The experts were verbally invited for an interview and they gladly accepted the offer. They were interviewed independently. As the session started, they were briefly explained about the research background and the guideline. The interview sessions were audio-recorded upon their consents. Each interview took about an hour. After the interview sessions, the recorded interview data were then transcribed into raw text format and later were analysed using contents analysis. The results were then used to improve the preliminary guideline.

\subsubsection{Data Analysis}

Generally, both experts agreed on the stipulated factors, elements and conditions. Below are their comments and suggestions on the preliminary guideline:

a) Instructor

- Background

Expert A suggested that if the CM instructor also writes the case by him or herself, he or she should also possess good narrative writing skill. This is because a case writer should be able to write stories that fascinate students without affecting the main objective of the case.

\section{- Personality}

Expert B believes that an instructor should be confident while conducting case discussions to gain students' trust. By gaining the students' trust, T\&L could become more effective. Hesitancy in giving feedback or answers would demoralise students in trusting the instructor and thus affects the efficacy of CM.

- Role

One of the instructor's roles is to encourage students to involve actively in the case discussions. Both Expert A and B agreed on this matter. Expert B highlighted that technical people are usually known as introverts and communicate less with colleagues. They would indulge into their own work and rarely interact with others. Therefore, the encouragement given by instructors during discussions is able to develop students' interpersonal skills and produce more people-oriented software engineers.

b) Student

- Personality (Interest)

Expert B suggested that students should have a strong interest to involve themselves in the discussion activities. If there is no interest, the students will remain quiet and resist any involvement either in class or group discussions. This will affect the learning objective through CM.

- Personality (Attention)

Expert B stated that each student should give full attention during CM discussions. Otherwise, the efficacy of T\&L will be affected.

\section{- $\quad$ Mixed group (Role in forming group)}

Expert B believed that in forming groups, not only there should be a mixed group of genders but the group members should also include a mix of various work backgrounds. This characteristic would be useful during the discussions whereby each of them could share experiences, suggestions and views that benefit the whole class.

c) Case

Cases should be equipped with teaching notes (Razali, Zainal, \& Chitsaz, 2012). Teaching notes contain teaching objectives, reading resources, best practices in handling discussions, model questions and answers as well as any related supporting documents such as software project artefacts. Expert A advocated that the teaching notes are indeed important and need to be a part of the guideline. Teaching notes in CM are useful during preparation and execution. Instructors could use teaching notes in preparing case manuals for students' reference. The manuals could also contain questions about the case as guidance in preparing answers and in writing the initial reports.

\section{Results}

This study has attempted to gather the important factors and the corresponding elements and conditions that 
contribute to an effective use of CM in T\&L SE courses. The factors and elements were gathered from a theoretical study as well as a series of surveys to form a preliminary guideline. The preliminary guideline was then validated through two expert reviews sessions and later enhanced based on the experts' recommendations to become the final guideline. Figure 3 illustrates the final guideline as a framework that outlines the main factors and their interrelationships with each other.

There are four main factors involved in the guideline, namely Case, Instructor, Student and Environment. Each factor contains a set of elements, which possess a number of conditions as depicted in Table 1. The table also indicates the sources from which each element was gathered. The four factors are then grouped under three aspects namely Environment, Process and Product. Since Environment implies a wide context, the 'Environment' theme used in earlier studies (Razali \& Zainal, 2013a, 2013b) was changed to 'Infrastructure' to disambiguate it from the Environment aspect. The three aspects interact or have certain functional relations with each other. Together as a whole, they form the guideline of using CM in T\&L SE. The following paragraphs briefly describe the guideline according to the aspects.

\subsection{Environment}

The Environment aspect represents the context or surrounding where $\mathrm{CM}$ is implemented. It comprises People and Infrastructure. The factors under People are Instructor and Student. Both factors interact with each other and have three elements related to them respectively, namely Personality, Background and Role. Each element has its corresponding conditions as shown in Table 1 . The Personality element represents the individual characteristics that Instructor or Student should possess for a successful CM Implementation. For example, Instructor should be happy and cheerful, fair and generous in selecting and assessing students. As for Student, he or she should be confident and has interest in CM. The Background element denotes the experience, skills and knowledge owned by Instructor and Student. For instance, Instructor must have worked in industry and understand SE very well. Working experience is optional to Student, however he or she should possess basic knowledge of SE. The guideline also suggests the Role that Instructor and Student should play. For example, Student should read and analyse the Case prior to discussion time and write a report. Student should also form a group of three to five members with a mixture of both genders and elect a leader. Student should later be involved in brainstorming sessions and present the solutions, which requires him or her to be critical and analytical thinkers. Among others, Instructor should explain the case, recognise Student's personality, control and conclude the discussions.

Another factor of Environment aspect is Infrastructure, which represents the equipment used and structure of the class. It consists of three elements, namely Seating Arrangement, Class Size and Teaching Aide. Infrastructure influences CM Implementation. For example, if a class size is too large and the seating arrangement is inappropriate, CM Implementation might not be effective. If Instructor has a very low volume voice, he or she can use a microphone while delivering the Case. Another possible aide is using buzzers to replace hand raising mechanism in the classroom.

\subsection{Process}

The Process aspect outlines the phases involved, which include Case Preparation and CM Implementation. The elements of Case Preparation were obtained from the earlier study (Razali, Zainal, \& Chitsaz, 2012) whilst CM Implementation were gathered from various sources, as described in Section 2 (Garg \& Varma, 2007; Jianmin \& Jian, 2010). This aspect links the Environment and Product aspects. Case Preparation that involves Instructor outlines the steps in preparing the Case, which starts from Setting up, Execution and finally, Wrapping up. The output from Case Preparation is Product. The Product aspect is then used in CM Implementation that takes place after Case Preparation. CM implementation consists of three phases, namely before, during and after. The specific conditions of the phases are described under Role of Instructor and Student in Table 1. CM implementation involves both Instructor and Student, which effectiveness is influenced by Infrastructure.

\subsection{Product}

Product is the output of Case Preparation. It comprises the Case itself and its corresponding Teaching Note. Both are used in CM Implementation and need to be updated from time to time as required by the curriculum. The Case has specific elements and each element describes the conditions that must be fulfilled in order for CM to be effective. The details can be found in Table 1. For example, the Case should comply with SE curriculum, as stipulated in ACM/IEEE SE curriculum guidelines (Joint Task Force on Computing Curricula, 2004) and Software Engineering Body of Knowledge (SWEBOK). The Case should be written in the native language so that local students could understand and empathise the story better. As SE terminology and meanings are mainly in English, the English version of the Case is also needed for students to understand the context. In addition, the Case that is included in written examination should be complete, precise and short due to time constraints. In 
general, Case materials are recommended to be printed. However, if the Case is lengthy or more supportive materials are needed, the Case can be represented in multimedia formats. Images should be used appropriately to avoid overdo presentation. In addition, the Case comes together with Teaching Note. The note is intended to guide instructors in delivering and discussing the Case, as it provides teaching objectives, reading materials, suggestions on case implementation, sample questions and answers as well as other supporting documents such as software artefacts. CM can be used as the only T\&L method if the students have strong SE knowledge. Otherwise, it can be paired with conventional T\&L methods.

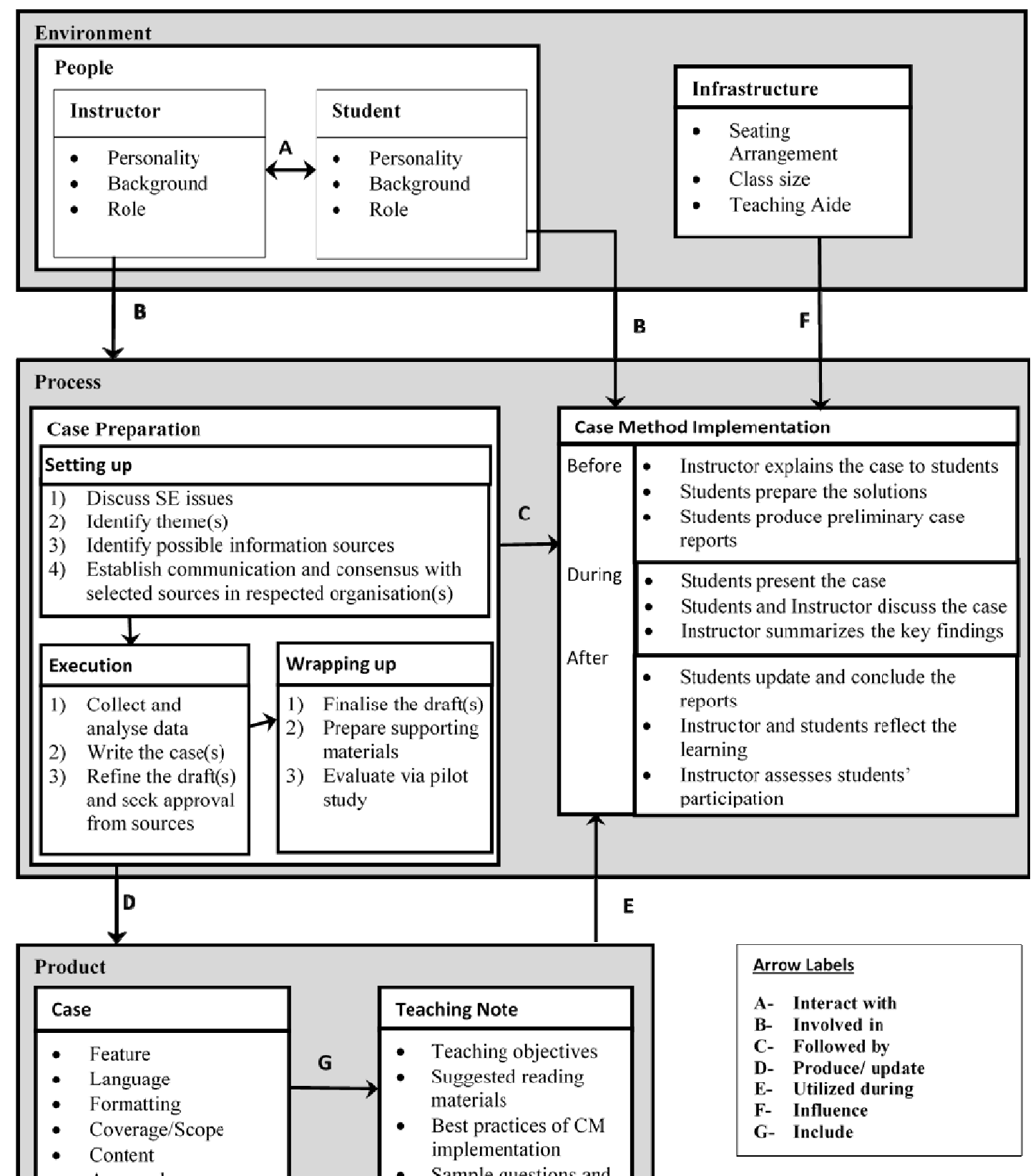

- Approach

- Written Assessment
- Sample questions and answers

- Related supporting documents
Note: SE = Software

Engineering

Figure 3. The framework of using case method in software engineering courses 
Table 1. The factors, elements and conditions for using case method in software engineering courses

\begin{tabular}{|c|c|c|c|c|c|}
\hline Factor & Element & Characteristics/Conditions & $\begin{array}{l}\text { Theoretical } \\
\text { Study }\end{array}$ & Surveys & $\begin{array}{l}\text { Expert } \\
\text { Reviews }\end{array}$ \\
\hline \multirow[t]{24}{*}{ Case } & \multirow[t]{3}{*}{ Feature } & Realism & $\checkmark$ & $\checkmark$ & $\checkmark$ \\
\hline & & Local scenario & $\checkmark$ & $\checkmark$ & $\checkmark$ \\
\hline & & Familiar characters & $\checkmark$ & $\checkmark$ & $\checkmark$ \\
\hline & \multirow[t]{2}{*}{ Language } & $\begin{array}{l}\text { Native language to understand story line } \\
\text { (for non-English native speakers) }\end{array}$ & & $\checkmark$ & $\checkmark$ \\
\hline & & $\begin{array}{l}\text { English language to understand the } \\
\text { storyline within SE context }\end{array}$ & & $\checkmark$ & $\checkmark$ \\
\hline & \multirow[t]{5}{*}{ Formatting } & Printed text & $\checkmark$ & $\checkmark$ & $\checkmark$ \\
\hline & & $\begin{array}{l}\text { Use multimedia elements, if text format } \\
\text { is too long or require supporting } \\
\text { information }\end{array}$ & $\checkmark$ & $\checkmark$ & $\checkmark$ \\
\hline & & Include meaningful images & $\checkmark$ & $\checkmark$ & $\checkmark$ \\
\hline & & $\begin{array}{l}\text { Printed } 3-5 \text { pages long, single column } \\
\text { (on A4 paper) }\end{array}$ & & $\checkmark$ & $\checkmark$ \\
\hline & & Single spacing & & $\checkmark$ & $\checkmark$ \\
\hline & \multirow{5}{*}{$\begin{array}{l}\text { Coverage/ } \\
\text { scope }\end{array}$} & Within a single organisation & & $\checkmark$ & $\checkmark$ \\
\hline & & Cover various issues and perspectives & & $\checkmark$ & $\checkmark$ \\
\hline & & $\begin{array}{l}\text { Present SE introductory topics in } \\
\text { modular/short-story forms }\end{array}$ & $\checkmark$ & & $\checkmark$ \\
\hline & & $\begin{array}{l}\text { One session includes one case covering } \\
\text { one main topic }\end{array}$ & $\checkmark$ & $\checkmark$ & $\checkmark$ \\
\hline & & $\begin{array}{l}\text { Comprise several cases covering } \\
\text { different topics }\end{array}$ & $\checkmark$ & $\checkmark$ & $\checkmark$ \\
\hline & \multirow[t]{9}{*}{ Content } & Simple & $\checkmark$ & $\checkmark$ & $\checkmark$ \\
\hline & & Attracts students' interests & $\checkmark$ & $\checkmark$ & $\checkmark$ \\
\hline & & $\begin{array}{l}\text { Comply to SE curriculum contents, } \\
\text { format and course objectives }\end{array}$ & $\checkmark$ & & $\checkmark$ \\
\hline & & $\begin{array}{l}\text { Contain SE basic principles and } \\
\text { concepts }\end{array}$ & $\checkmark$ & $\checkmark$ & $\checkmark$ \\
\hline & & $\begin{array}{l}\text { Created specifically for the designated } \\
\text { students }\end{array}$ & $\checkmark$ & & $\checkmark$ \\
\hline & & $\begin{array}{l}\text { Include the relevant and current } \mathrm{SE} \\
\text { issues }\end{array}$ & $\checkmark$ & $\checkmark$ & $\checkmark$ \\
\hline & & $\begin{array}{l}\text { Synchronised with other SE course } \\
\text { materials }\end{array}$ & $\checkmark$ & $\checkmark$ & $\checkmark$ \\
\hline & & Moderate difficulty & $\checkmark$ & $\checkmark$ & $\checkmark$ \\
\hline & & Contain practical elements & $\checkmark$ & $\checkmark$ & $\checkmark$ \\
\hline
\end{tabular}




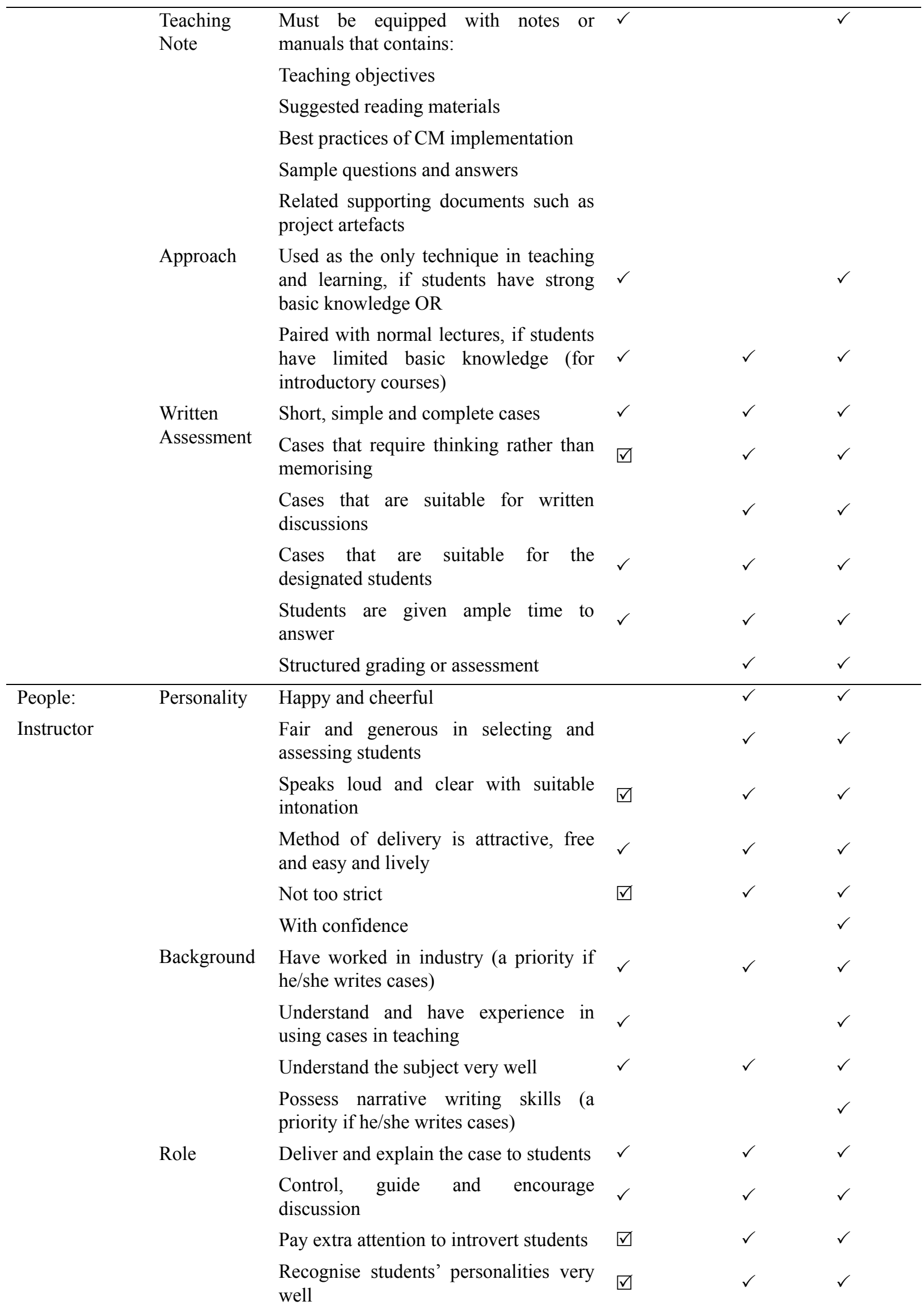




\begin{tabular}{|c|c|c|c|c|c|}
\hline & & $\begin{array}{l}\text { Summarise at the end of a discussion } \\
\text { without giving the ideal solutions }\end{array}$ & $\checkmark$ & $\checkmark$ & $\checkmark$ \\
\hline & & Move around while conducting the case & $\nabla$ & $\checkmark$ & $\checkmark$ \\
\hline & & $\begin{array}{l}\text { Provide feedback during discussion and } \\
\text { rewards students' involvements }\end{array}$ & $\checkmark$ & $\checkmark$ & $\checkmark$ \\
\hline & & $\begin{array}{l}\text { Continuously improve case teaching } \\
\text { skills }\end{array}$ & $\checkmark$ & & $\checkmark$ \\
\hline People: & \multirow[t]{6}{*}{ Personality } & Participate voluntarily & $\nabla$ & $\checkmark$ & $\checkmark$ \\
\hline \multirow[t]{23}{*}{ Student } & & Have highly competitive nature & $\nabla$ & $\checkmark$ & $\checkmark$ \\
\hline & & Having confidence & $\nabla$ & $\checkmark$ & $\checkmark$ \\
\hline & & Being an extrovert student & & $\checkmark$ & $\checkmark$ \\
\hline & & Having interests in $\mathrm{CM}$ & & & $\checkmark$ \\
\hline & & Pay full attention to discussions & & & $\checkmark$ \\
\hline & \multirow[t]{3}{*}{ Background } & $\begin{array}{l}\text { Possess working experience (an added } \\
\text { advantage) }\end{array}$ & $\nabla$ & $\checkmark$ & $\checkmark$ \\
\hline & & $\begin{array}{l}\text { Possess basic knowledge on } \mathrm{SE} \\
\text { processes }\end{array}$ & $\checkmark$ & $\checkmark$ & $\checkmark$ \\
\hline & & $\begin{array}{l}\text { Possess knowledge on SE basic } \\
\text { concepts }\end{array}$ & $\checkmark$ & $\checkmark$ & $\checkmark$ \\
\hline & \multirow[t]{15}{*}{ Role } & Prior to Class Preparation & & & \\
\hline & & $\begin{array}{l}\text { Read and analyse the case within a } \\
\text { specified period (approximately one } \\
\text { page per day) }\end{array}$ & $\checkmark$ & $\checkmark$ & $\checkmark$ \\
\hline & & $\begin{array}{l}\text { Write a preliminary report which } \\
\text { contains answers to the case questions }\end{array}$ & $\checkmark$ & $\checkmark$ & $\checkmark$ \\
\hline & & Group Formation & & & \\
\hline & & Self-form a group & $\checkmark$ & $\checkmark$ & $\checkmark$ \\
\hline & & Select 3-5 people per group & $\checkmark$ & $\checkmark$ & $\checkmark$ \\
\hline & & $\begin{array}{l}\text { Assure group members are a mixture of } \\
\text { gender and work experiences }\end{array}$ & & $\checkmark$ & $\checkmark$ \\
\hline & & Appoint a leader and divide tasks & $\checkmark$ & $\checkmark$ & $\checkmark$ \\
\hline & & Discussion & & & \\
\hline & & Involved in the brainstorming sessions & $\nabla$ & $\checkmark$ & $\checkmark$ \\
\hline & & Think analytically and critically & $\nabla$ & $\checkmark$ & $\checkmark$ \\
\hline & & Present solutions in the class & $\checkmark$ & $\checkmark$ & $\checkmark$ \\
\hline & & Wear nametags during class discussions & $\checkmark$ & $\checkmark$ & $\checkmark$ \\
\hline & & $\begin{array}{l}\text { Look at the problem from various } \\
\text { perspectives }\end{array}$ & $\square$ & $\checkmark$ & $\checkmark$ \\
\hline & & $\begin{array}{l}\text { Write an updated report including the } \\
\text { conclusion and reflection information } \\
\text { as discussed in the class }\end{array}$ & $\checkmark$ & $\checkmark$ & $\checkmark$ \\
\hline \multirow[t]{3}{*}{ Infrastructure } & \multirow{2}{*}{$\begin{array}{l}\text { Seating } \\
\text { arrangement }\end{array}$} & Face the white/blackboard & $\nabla$ & $\checkmark$ & $\checkmark$ \\
\hline & & $\begin{array}{l}\text { Arched in a horseshoe or ' } U \text { ' shape } \\
\text { towards the front }\end{array}$ & $\nabla$ & $\checkmark$ & $\checkmark$ \\
\hline & Class size & Not too large & $\checkmark$ & $\checkmark$ & $\checkmark$ \\
\hline
\end{tabular}




\section{Teaching Use microphone and loud speakers, if aide $\quad$ required (due to low volume or unclear voice) \\ Use buzzers to improvise the hand raising mechanism when answering questions in the class}

\section{$\nabla$}

Note: $\nabla$ depicts that the data was from general sources about CM.

Figure 3 and Table 1 together constitute the guideline of using CM in SE courses. The former shows the main factors and their interrelationships whereas the latter describes the conditions that the factors should fulfil in ensuring CM in T\&L SE successful. The guideline is intended to direct more meaningful learning among SE students through the use of $\mathrm{CM}$. Although quite conclusive, the guideline is seen as a dynamic entity which can be revised over time when more evidence is gathered from the field.

\section{Threats to Validity}

The four kinds of validity that must be protected in empirical studies are discussed below:

\subsection{Internal Validity}

The participants were students in the university where the study was conducted (convenient sampling). In addition, the students were in contact with each other. Their answers therefore might have been biased either in positive or negative ways. On the other hand, the students were considered as the most appropriate candidates because they were exposed and trained on using CM in SE courses. To reduce the threat, the students were advised to give opinions and comments as sincerely as possible.

\subsection{External Validity}

Due to academic time and resource constraints, the cases given to the participants were not many and extensive. In average, there were about three to five cases with 3-10 pages long. The cases however are believed to be sufficient for participants to experience using CM in T\&L SE courses.

\subsection{Construct Validity}

Surveys and qualitative measures by their nature are retrospective. Therefore, there was a risk that the participants responded based on what they thought they did rather than what they actually did. Advising the participants to complete the survey questionnaire as soon as they finished the case discussions could have reduced this threat, as the participants still remembered of what they experienced during the process.

\subsection{Conclusion Validity}

The participants had different ability and experience. Thus, there was a risk that the results might have been influenced greatly by individual differences. As a qualitative study, the variation however could provide richer data for the analysis.

\section{Concluding Remarks}

This paper has presented a guideline of adopting CM in T\&L SE courses. The guideline contains a set of factors, elements and conditions for four main contributing factors, namely Case, Instructor, Student and Infrastructure, categorised under three aspects which are Environment, Process and Product. The guideline was derived from a series of theoretical and empirical work. The guideline can be used by SE instructors to conduct the courses using CM. Future work can be done in refining the types of cases that are suitable to be used as well as the assessment methods in CM for T\&L SE.

\section{Acknowledgements}

This work was funded by the Universiti Kebangsaan Malaysia (UKM) Action/Strategic Research Funds (PTS-086-2009 \& PTS-2012-064). The authors thank the participants involved in the study.

\section{References}

Bolinger, J. (2011). Connecting reality with theory - An approach for creating integrative industry case studies in the software engineering curriculum. Paper presented at the Annual Frontiers in Education, Rapid City, SD, 12-15 Oct. 2011. http://dx.doi.org/10.1109/FIE.2011.6142882

Bolinger, J., Yackovich, K., Ramnath, R., Ramanathan, J., \& Soundarajan, N. (2010). From Student to Teacher: 
Transforming Industry Sponsored Student Projects into Relevant, Engaging, and Practical Curricular Materials. Paper presented at the Transforming Engineering Education: Creating Interdisciplinary Skills for Complex Global Environments, IEEE, Dublin, 6-9 April 2010. http://dx.doi.org/10.1109/TEE.2010.5508872

Burge, J., \& Troy, D. (2006). Rising to the Challenge: Using business-oriented case studies in software engineering education. Paper presented at the 19th Conference on Software Engineering Education and Training, HI, USA, 19-21 April 2006. http://dx.doi.org/10.1109/CSEET.2006.29

CAPAM. (2010). Overview of Case Study Models and Methodology: Commonwealth Association for Public Administration and Management (CAPAM).

Carroll, J. M., \& Rosson, M. B. (2006). Case Studies as Minimalist Information. Professional Communication, IEEE Transactions on, 49(4), 297-310. http://dx.doi.org/10.1109/tpc.2006.885836

Dooley, A. R., \& Skinner, W. (1977). Casing Casemethod Methods. The Academy of Management Review, 2(2), 277-289. http://dx.doi.org/10.2307/257909

Fuller, A., Croll, P., \& Limei, D. (2002). A new approach to teaching software risk management with case studies. Paper presented at the Proceedings of the 15th Conference on Software Engineering Education and Training, Covington, KY, 25-27 Feb. 2002. http://dx.doi.org/10.1109/CSEE.2002.995213

Garg, K., \& Varma, V. (2007). A Study of the Effectiveness of Case Study Approach in Software Engineering Education. Paper presented at the 20th Conference on Software Engineering Education \& Training, Dublin, Ireland, 3-5 July 2007. http://dx.doi.org/10.1109/CSEET.2007.8

Garg, K., \& Varma, V. (2009). Case Studies as Assessment Tools in Software Engineering Classrooms. Paper presented at the 22nd Conference on Software Engineering Education and Training, Hyderabad, Andhra Pradesh, 17-20 Feb. 2009. http://dx.doi.org/10.1109/CSEET.2009.41

Garg, K., Varma, V., Giridhar, K. N., \& Mishra, A. K. (2006). Security: Bridging the Academia-Industry Gap Using a Case Study. Paper presented at the 13th Asia Pacific of Software Engineering Conference, Kanpur, 6-8 Dec. 2006. http://dx.doi.org/10.1109/APSEC.2006.52

Golich, V., Boyer, M., Franko, P., \& Lamy, S. (2001). The ABCs of Case Teaching A guide to the art of case teaching by four Pew Fellows. Institute of the Study of Diplomacy.

Herreid, C. F. (2005). Because Wisdom Can't Be Told: Using Case Studies to Teach Science. Peer Review, 7 , 30-31, Winter 2005. Retrieved from http://www.aacu.org/peerreview/pr-wi05/pr-wi05realitycheck.cfm

Hilburn, T. B., \& Towhidnejad, M. (2007). A Case for Software Engineering. Paper presented at the Proceedings of the 20th Conference on Software Engineering Education \& Training, Dublin, Ireland. Retrieved from $\mathrm{http}$ ://ieeexplore.ieee.org/stamp/stamp.jsp?arnumber $=4271596$

Hilburn, T. B., Towhidnejad, M., Nangia, S., \& Li, S. (2006). A Case Study Project for Software Engineering Education. Paper presented at the 36th Annual Frontiers in Education Conference, San Diego, CA, 27-31 Oct. 2006. http://dx.doi.org/10.1109/FIE.2006.322302

Jia, Y. (2010). Improving Software Engineering Courses with Case Study Approach. Paper presented at the The 5th International Conference on Computer Science \& Education, Hefei, China, August 24-27, 2010. http://dx.doi.org/10.1109/ICCSE.2010.5593593

Jianmin, Z., \& Jian, L. (2010). Teaching Software Engineering Using Case Study. Paper presented at the 2010 International Conference on Biomedical Engineering and Computer Science, Wuhan, 23-25 April 2010. http://dx.doi.org/10.1109/ICBECS.2010.5462378

Joint Task Force on Computing Curricula. (2004). Software Engineering 2004: Curriculum Guidelines for Undergraduate Degree Programs in Software Engineering, Computing Curricula Series. Retrieved from http://sites.computer.org/ccse/SE2004Volume.pdf

Konsky, B. R., Ivins, J., \& Gribble, S. J. (2007). Engaging undergraduates in discussions about ethics in computing. Proceedings of the ninth Australasian conference on Computing education, 66, 163-169. Retrieved from http://dl.acm.org/citation.cfm?id=1273692

Krippendorff, K. (2013). Content Analysis: An Introduction to Its Methodology (3rd ed.). Los Angeles: SAGE Publications.

Leenders, M. R., Erskine, J. A., \& Mauffette-Leenders, L. A. (2007). Learning with Cases. Richard Ivey School 
of Business, University of Western Ontario.

Lin, Z. (2010). Applying case method approach to a unified modeling language curriculum. Paper presented at the 2nd International Conference on Education Technology and Computer, 22-24 June 2010. http://dx.doi.org/10.1109/ICETC.2010.5529652

Ramnath, S., \& Dathan, B. (2008). Evolving an integrated curriculum for object-oriented analysis and design. SIGCSE Bull., 40(1), 337-341. http://dx.doi.org/10.1145/1352322.1352252

Razali, R., \& Zainal, D. A. P. (2013a). Assessing Students' Acceptance of Case Method in Software Engineering Education-A Survey. Procedia-Social and Behavioral Sciences, 93(0), 1562-1568. http://dx.doi.org/10.1016/j.sbspro.2013.10.082

Razali, R., \& Zainal, D. A. P. (2013b). Success factors for using case method in teaching and learning software engineering. International Education Studies, 6(6), 191-201. http://dx.doi.org/10.5539/ies.v6n6p191

Razali, R., Zainal, D. A. P., \& Chitsaz, M. (2012). Developing Industrial Cases for Teaching Software Engineering-A Lesson Learned. Asian Social Science, 8(16), 215-221. http://dx.doi.org/10.5539/ass.v8n16p215

Rongchun, C., \& Lixin, X. (2008). Integrated Application of Project Cases in Programming Course. Paper presented at the The 9th International Conference for Young Computer Scientists, Hunan, 18-21 Nov. 2008. http://dx.doi.org/10.1109/ICYCS.2008.417

Shackelford, R., McGettrick, A., Sloan, R., Topi, H., Davies, G., Kamali, R., . . . Lunt, B. (2005). ACM Computing Curricula 2005: The Overview Report. Paper presented at the Proceedings of the 37th SIGCSE technical symposium on Computer science education, 30 September 2005. Retrieved from http://dl.acm.org/citation.cfm?id=1121482

Smith, G., Vega, L. C., \& McCrickard, D. S. (2008). Education and design: using human-computer interaction case studies to learn. Proceedings of the 46th Annual Southeast Regional Conference on XX, 346-351. $\mathrm{http} / / / \mathrm{dx}$.doi.org/10.1145/1593105.1593197

Sommerville, I. (2010). Software Engineering (9th ed.). Boston: Addison-Wesley.

Strach, P., \& Everett, A. M. (2008). Transforming research case studies into teaching cases. Qualitative Research in Organizations and Management: An International Journal, 3(3), 199-214. http://dx.doi.org/10.1108/17465640810920287

Tan, W.-K., \& Teo, H.-H. (2009). Training students to be innovative information systems developers: Synergizing project-based learning with problem-based learning. Paper presented at the Proceedings of the Special Interest Group on Management Information System's 47th Annual Conference on Computer Personnel Research, Limerick, Ireland, May 28-30, 2009. http://dx.doi.org/10.1145/1542130.1542136

Taran, G., Miller, R., Seela, R., \& Shojaeddini, A. (2009). Using Rich Multimedia Case Studies: Developing a Scalable Authoring Platform for Academia and Industry. Paper presented at the 22nd Conference on Software Engineering Education and Training, 17-20 Feb. 2009. http://dx.doi.org/10.1109/CSEET.2009.45

Varma, V., \& Garg, K. (2005). Case studies: the potential teaching instruments for software engineering education. Paper presented at the Proceedings of the 5th International Conference on Quality Software, Melbourne, Australia, 19-20 Sept. 2005. http://dx.doi.org/10.1109/QSIC.2005.18

Volpe, D. G. (2002). Case Studies. The Handbook for Economics Lecturers. Retrieved September 2012, from http://www.economicsnetwork.ac.uk/handbook

Wang, Z., \& Yang, C. (2010). Research on Case Learning System for Engineering Subject-Software Engineering as an Example. Paper presented at the 10th IEEE International Conference on Computer and Information Technology, Bradford, June 29-July 1 2010. http://dx.doi.org/10.1109/CIT.2010.357

Yu, J. (2010). Improving software engineering courses with case study approach. Paper presented at the 5th International Conference on Computer Science and Education, Hefei, 24-27 Aug. 2010. http://dx.doi.org/10.1109/ICCSE.2010.5593593

\section{Note}

Note 1. Bahasa Malaysia is the national language of Malaysia. 


\section{Copyrights}

Copyright for this article is retained by the author(s), with first publication rights granted to the journal.

This is an open-access article distributed under the terms and conditions of the Creative Commons Attribution license (http://creativecommons.org/licenses/by/3.0/). 